\title{
Spiritual Bypass: A Preliminary Investigation
}

By: Craig S. Cashwell*, Harriet L. Glosoff, and Chereé Hammond.

Cashwell, C. S., Glosoff, H. L., \& Hammonds, C. (2011). Spiritual Bypass: A Preliminary Investigation. Counseling and Values, 54, 162-174.

"This is the peer reviewed version of the following article: Cashwell, C. S., Glosoff, H. L., \& Hammonds, C. (2011). Spiritual Bypass: A Preliminary Investigation. Counseling and Values, 54, 162-174, which has been published in final form at http://dx.doi.org/10.1002/j.2161-007X.2010.tb00014.x. This article may be used for noncommercial purposes in accordance with Wiley Terms and Conditions for Self-Archiving."

\begin{abstract}
:
The phenomenon of spiritual bypass has received limited attention in the transpersonal psychology and counseling literature and has not been subjected to empirical inquiry. This study examines the phenomenon of spiritual bypass by considering how spirituality, mindfulness, alexithymia (emotional restrictiveness), and narcissism work together to influence depression and anxiety among college students. Results suggested that mindfulness and alexithymia accounted for variance in depression beyond what is accounted for by spirituality and that all 3 factors (mindfulness, alexithymia, and narcissism) accounted for variance in anxiety beyond what is accounted for by spirituality. Implications for counselors are provided.
\end{abstract}

Keywords: spiritual bypass | psychology | counseling | mindfulness | alexithymia | narcissism | anxiety | depression | college

\section{Article:}

Spirituality and religion play an important role in the lives of a significant number of Americans. Researchers have found that $96 \%$ of Americans believe in a Higher Power, over 90\% pray, $69 \%$ are members of a religious community, and $43 \%$ have attended a religious service within the past 7 days (Princeton Religion Center, 2000). Furthermore, spirituality is a central component of an individual's culture and development, both of which are considered core tenets of the counseling profession. As a result, spirituality continues to be a vital and growing area of interest within professional counseling and counselor education (Cashwell \& Young, 2005).

The assessment of client spirituality, in particular, seems vital (Harper \& Gill, 2005). It is essential that spiritually competent counselors accurately assess the importance of spirituality in clients' lives and how this affects their presenting issues. Spirituality is deeply personal, developmental, and often difficult to describe in words, however, and an accurate assessment is often difficult. To further complicate the assessment process, it is essential that spirituality be assessed in ways that respect the belief systems and values of the client, even when these beliefs and values diverge from those of the counselor. It is easy to believe that clients who report strong convictions, a disciplined spiritual practice, and transpersonal experiences have a high level of spirituality. Similarly, it is likely that such clients would score high on existing paper-and- 
pencil measures of spirituality. Researchers (Briggs \& Shoffner, 2006; Young, Cashwell, \& Shcherbakova, 2000) have demonstrated that people who score high on paper-and-pencil measures of spirituality tend to score lower on measures of depression and anxiety, two of the most common client presenting issues. It is possible, however, that these assessments fail to capture the complexity of the spiritual process.

\section{Spiritual Bypass}

In particular, spiritual bypass is a developmental phenomenon that may shed light on the assessment process. The term spiritual bypass refers to the unhealthy misuse of the spiritual life to avoid dealing with psychological difficulties (Welwood, 2000; Whitfield, 2003). Originally described in the recovery literature by Whitfield (2003), the term became popular in the transpersonal psychology literature and has only recently been discussed in the counseling field (Cashwell, Bentley, \& Yarborough, 2007; Cashwell, Myers, \& Shurts, 2004). In essence, spiritual bypass serves an avoidance function; it allows the individual to avoid the often painful and difficult psychological work of healing old wounds. For example, a client reports that she uses most of her spare time participating in church projects and has strong spiritual convictions, transpersonal experiences, and a disciplined spiritual practice. What is not readily apparent, however, is that this client uses these practices as an unconscious way to avoid dealing with her early experiences of verbal abuse or the shame she associates with her well-hidden gambling addiction. As such, the person in spiritual bypass actually might be best conceptualized as in a state of developmental arrest, which may result in increased psychological symptoms. Such a person would be likely to score high on a paper-and-pencil measure of spirituality, or would respond to an initial assessment of spirituality in a way that could easily lead a counselor to believe that he or she has a strong (and healthy) spiritual life. Although researchers have found significant relationships between spirituality and such mental health issues as depression and anxiety (Briggs \& Shoffner, 2006; Young et al., 2000), it is possible that the true relationships between spirituality and psychological symptoms are truncated by respondents who are in spiritual bypass.

Spiritual bypass has been hypothesized to manifest in a number of ways, such as extreme external locus of control and abdication of personal responsibility, spiritual obsession, and the repression of emotions, as well as spiritual narcissism - an "I'm enlightened and you're not" syndrome (Cashwell et al., 2007; Welwood, 2000; Whitfield, 2003). The genuine spiritual path involves awareness and acceptance of present moment circumstances. In contrast, spiritual bypass involves a denial of at least some aspects of this experience. For example, the person in spiritual bypass may be misusing spiritual beliefs to defend emotional repression or misusing spiritual narcissism to avoid a genuine examination of thoughts and feelings of insecurity. As such, spiritual bypass essentially involves a disavowal of at least some aspects of "what is." Thus, mindfulness, in addition to emotional repression and narcissism, seems an important area to consider when working with clients who report spirituality as being an important part of their lives.

One limitation of the spiritual bypass literature is that it has not yet been critically examined. A review of relevant databases reveals a number of writings on spiritual bypass. None, however, involve an attempt to empirically examine the phenomenon. Because spiritual development 
occurs concomitant with emotional, cognitive, and interpersonal development and because it is important to consider the genuine spiritual path as a path of "what is," it is important to consider such constructs as alexithymia (emotional restrictive- ness), mindfulness, and narcissism along with spirituality. The purposes of the current study, then, are to (a) examine the phenomenon of spiritual bypass by considering self-reported levels of spirituality not in a vacuum, but in the context of other relevant constructs, including alexithymia (emotional repression), narcissism, mindfulness, depression, and anxiety and (b) consider how these constructs (spirituality, alexithymia, mindfulness, and narcissism) work within a multivariate model to predict levels of depression and anxiety.

\section{Method}

Sample

The convenience sample consisted of 339 undergraduate and graduate students enrolled in two large public universities in the southern United States. Fifty-four percent (54\%) of the sample participants were in their $4^{\text {th }}$ year of undergraduate school, and $46 \%$ were in graduate school. Of the 339 participants included in the study, 240 (70.8\%) were female and 99 (29.2\%) were male. All participants ranged in age from 18 to 48 years, with the average age of 22.46 years $(S D=4.18)$. The participant pool was composed of $57(16.8 \%)$ students who identified themselves as African American, 26 (7.7\%) Asian or Pacific Islander, 236 (69.8\%) European American (White), 5 (1.5\%) Hispanic, 2 (0.6\%) Native American or American Indian, and 12 $(3.6 \%)$ other ethnicity (one person did not include this information).

\section{Procedure}

Participants were recruited from two large public universities in the southern United States. Data were collected both within and outside of classroom set- tings. Classroom instructors were contacted and permission was requested to collect data within the classroom. Some instructors allowed data to be collected in one sitting from intact classrooms. Other instructors allowed the researchers (the authors) to present information in person or by e-mail about the research and to provide packets to students containing research instruments and consent forms. Students completed the assessments on their own time and returned the packets to the department secretary. Regardless of the data collection method used, all students were clearly informed that participation was voluntary and were given the option to opt out of participating at any time without consequence.

\section{Instrumentation}

Participants completed the following instruments to measure the predictor (spirituality, mindfulness, alexithymia, and narcissism) and criterion (depression and anxiety) variables.

Spirituality Assessment Scale (SAS; Howden, 1992). The SAS is a 28-item self-assessment scale, developed by Howden (1992), that measures four components or elements of spirituality: purpose and meaning in life, innerness and inner resources, unifying interconnectedness, and transcendence. Respondents are asked to indicate the response that best describes them in relation to 
each statement presented (e.g., "My inner strength is related to a belief in a Higher Power or Supreme Being"). Individuals rate items using a 6-point Likert scale ranging from strongly disagree (1) to strongly agree (6), with all statements being positively worded. Total SAS scores can range from 28 to 168 (Howden, 1992).

The measure's internal consistency reliability is strong (SAS's total scale Cronbach's alpha coefficient $=.92$; Howden, 1992). Coefficient alphas for the subscales (i.e., Purpose and Meaning, Innerness and Inner Resources, Unifying Interconnectedness, and Transcendence) among the current sample ranged from .71 to .84, with a median alpha of .79. The full scale alpha (.92) for the current sample reflected Howden's (1992) research. Because the internal consistency for the full scale was higher than for the subscales, the full scale was used as the unit of analysis. Factor analytic procedures provided evidence for construct validity (Howden, 1992). Stanard, Sandhu, and Painter (2000) also reported that the SAS has high face validity.

Five Factor Mindfulness Questionnaire (FFMQ; Baer, Smith, Hopkins, Krietemeyer, \& Toney, 2006). The FFMQ measures five facets of mindfulness: observing (noticing or attending to a variety of stimuli), describing (applying words to observed phenomena), acting with awareness (engaging attention fully on the current activity), nonjudging (refraining from evaluative labels about various observed phenomena), and nonreacting (noticing phenomena without having a reaction to it). The five dimensions form a total mindfulness score, which describes a global measure of mindfulness. The response format of the FFMQ is a 5-point Likert-type scale $(1=$ never or very rarely true, $5=$ very often or always true).

Researchers have found that the FFMQ measures distinct aspects of mindfulness and that the factors have strong internal consistency (Baer et al., 2006). Evidence exists of construct validity (via exploratory and confirmatory factor analyses) as well as convergent and discriminant validity (Baer et al., 2006). For the current sample, coefficient alphas ranged from .73 to .89 , with a median coefficient alpha of .86 .

Narcissistic Personality Inventory (NPI). The NPI is a 40-item assessment designed by Raskin and Terry (1988) to measure components/subscales of the narcissistic personality: Authority, Self-Sufficiency, Superiority, Exhibitionism, Exploitive, Vanity, and Entitlement (Raskin \& Terry, 1988). Individuals responded to each statement presented on a 5-point Likert-type scale, from not at all true of me (1) to completely true of me (5), indicating how closely each statement described them (e.g., "I insist upon getting the respect that is due me"). Total NPI scores can range from 40 to 200 .

According to del Rosario and White (2005), the NPI and its seven components/subscales have adequate stability with correlations for the seven components/subscales and the full-scale score, ranging from .57 to .81 ( $p<.01$, two-tailed). The NPI has demonstrated significant test-retest correlations for all subscales, and the full-scale score (the unit of analysis for this study) has strong evidence of internal consistency $(\alpha=.83)$. Factor analytic procedures and convergent and discriminant analyses provide support for the construct validity of the NPI (Emmons, 1984). 
Toronto Alexithymia Scale-20 (TAS-20; Bagby, Parker, \& Taylor, 1994; Bagby, Taylor, \& Parker, 1994). The TAS-20 is a 20-item instrument that measures a person's inability to express emotions verbally. It consists of three subscales: Difficulty Identifying Feelings, Difficulty Describing Feelings, and Externally Oriented Thinking. Participants are instructed to rate each of the items by circling the number that best describes them in relation to the statement presented (e.g., "People tell me to describe my feelings more"). The instrument is scored using a 5-point Likerttype scale, from not at all like me (1) to completely like me (5). Total TAS-20 scores can range from 20 to 100. Coefficient alpha has been reported previously as .81 for the total scale (Bagby, Parker, et al., 1994; Bagby, Taylor, et al., 1994), and the alpha for the current sample was .84. The TAS-20 has been cross-validated across different languages and among different populations (Parker, Taylor, \& Bagby, 2003; Taylor, Bagby, \& Parker, 2003), and evidence supports the construct and criterion validity of the TAS-20 (Meganck, Vanheule, \& Desmet, 2008; Taylor et al., 1988).

Center for Epidemiologic Studies Depression Scale (CES-D). The 10-item short version of the CES-D (CES-D10), a measure of unipolar depression, was used (Radloff, 1977). Participants respond to 10 statements that describe how often they experienced specific symptoms of depression during the past week. The test makes use of a 4-point Likert-type scale, from rarely or less than 1 day (0) to all of the time or 5-7 days (3). Total CES-D10 scores can range from 0 to 30. Andresen, Malmgren, Carter, and Patrick (1994) reported that the 10-item scale demonstrated good predictive accuracy when compared with the longer 20-item version (Cohen's kappa $=.97, p<.001)$. Test-retest reliability studies ranging over 2 to 8 weeks showed moderate correlations $(r=.51-.67)$, which is desirable for a test of symptoms that are expected to show change over time. Coefficient alpha for the current sample was .81. Scores on the CES-D10 have been found to correlate significantly (.73 to .89) with the Symptom Checklist-90, providing evidence of convergent validity (Weissman, Sholomskas, Pottenger, Prusoff, \& Locke, 1977).

Trimodal Anxiety Questionnaire (TAQ; Lehrer \& Woolfolk, 1982). The TAQ is a 36-item instrument used to measure behavioral (19 items), somatic (16 items), and cognitive (11 items) manifestations of anxiety. Individuals respond to each statement presented on a 9-point Likert-type scale, from never (0) to extremely often (8), indicating how often he or she experienced each situation described (e.g., "I keep busy to avoid uncomfortable thoughts"). Total TAQ scores can range from 0 to 288 .

According to Lehrer and Woolfolk (1982), split-half reliabilities for the three subscales (i.e., Behavioral, Somatic, and Cognitive) ranged from .83 to .85 for a sample of college students to .91 to .93 for a mixed clinical/ community sample. In addition, Scholing and Emmelkamp (1992) reported good internal consistency (alphas ranging from .83 to .92) for a sample of participants with social phobia. Scholing and Emmelkamp also reported that scores significantly differentiated a sample of adults with social phobias from a nonclinical sample of adults.

\section{Results}


First, descriptive statistics were obtained for all of the predictor and criterion variables. These results are presented in Table 1. Next, bivariate correlations and Cronbach's alpha coefficients were calculated for all of the study variables for this sample. The correlation matrix is presented in Table 2; alphas are presented on the diagonal. Although there were a large number of significant correlations, some of these were likely an artifact of sample size and may be of limited clinical significance. There were, however, a number of strong correlations between study variables that have both statistical and clinical significance. Similar to previous research findings, spirituality (total score) correlated significantly with both depression $(r=-.28)$ and anxiety $(r=-.33)$. Two aspects of mindfulness also had moderate bivariate correlations with the criterion variables. Scores on the subscale Acting with Awareness correlated significantly with both anxiety $(r=.36)$ and depression $(r=-.37)$, and scores on the subscale Nonjudging correlated significantly with both anxiety $(r=-.44)$ and depression $(r=-.41)$. All of these correlations are negative, indicating inverse relationships between each of these predictor and criterion variables.

Table 1

\begin{tabular}{lrr}
\multicolumn{3}{c}{ Descriptive Statistics for Predictor and Criterion Variables } \\
\hline \hline Variable & $\boldsymbol{M}$ & \multicolumn{1}{c}{$\mathbf{S D}$} \\
\hline Spirituality & 133.24 & 15.36 \\
Mindfulness-Total & 127.21 & 14.83 \\
Observing & 26.06 & 4.97 \\
Describing & 27.48 & 5.59 \\
Acting with Awareness & 26.16 & 5.39 \\
Nonjudging & 26.36 & 5.49 \\
Nonreacting & 21.14 & 3.62 \\
Alexithymia & 43.06 & 10.26 \\
Narcissism & 122.83 & 21.38 \\
Depression & 9.80 & 5.31 \\
Anxiety & 87.81 & 39.87 \\
\hline
\end{tabular}

Table 2

Bivariate Correlations and Cronbach's alpha Coefficients

\begin{tabular}{|c|c|c|c|c|c|c|c|c|c|c|}
\hline Variable & 1 & 2 & 3 & 4 & 5 & 6 & 7 & 8 & 9 & 10 \\
\hline 1. Spirituality & .92 & $.31^{* \star}$ & $.34^{* *}$ & $.24^{* *}$ & $.17^{\star \star}$ & $.26^{* *}$ & $-.40^{\star *}$ & $.18^{* *}$ & $-.28^{* *}$ & $-.33^{\star *}$ \\
\hline $\begin{array}{l}\text { 2. Observing } \\
\text { 3. Describing } \\
\text { 4. Acting with }\end{array}$ & & .75 & $\begin{array}{l}.19^{* *} \\
.89\end{array}$ & $\begin{array}{l}.04 \\
.31^{* *}\end{array}$ & $\begin{array}{l}-.07 \\
.19^{* *}\end{array}$ & $\begin{array}{l}.31^{* *} \\
.19^{* *}\end{array}$ & $\begin{array}{l}-.18^{\star *} \\
-.72^{\star *}\end{array}$ & $\begin{array}{l}.10 \\
.26^{\star *}\end{array}$ & -.02 & $\begin{array}{c}.03 \\
-.27^{\star *}\end{array}$ \\
\hline $\begin{array}{l}\text { Awareness } \\
\text { 5. Nonjudging } \\
6 . \text { Nonreacting } \\
\text { 7. Alexithymia } \\
\text { 8. Narcissism } \\
\text { 9. Depression } \\
\text { 10. Anxiety }\end{array}$ & & & & .87 & $\begin{array}{l}.35^{\star *} \\
.86\end{array}$ & $\begin{array}{l}.18^{\star *} \\
.15^{* \star} \\
.73\end{array}$ & $\begin{array}{l}-.36^{\star *} \\
-.31^{\star *} \\
-.15^{\star *} \\
.84\end{array}$ & $\begin{array}{r}.11 \\
.08 \\
.00 \\
-.10 \\
.93\end{array}$ & $\begin{array}{c}-.37^{\star *} \\
-.41^{\star *} \\
-.25^{\star *} \\
.38^{\star *} \\
-.05 \\
.81\end{array}$ & $\begin{array}{r}-.36^{\star *} \\
-.44^{\star *} \\
-.19^{\star *} \\
.46^{\star *} \\
-.14^{\star} \\
.57^{\star *} \\
.94\end{array}$ \\
\hline
\end{tabular}

Note. Cronbach's alpha coefficients are in boldface. ${ }^{*} p<.05{ }^{* *} p<.01$.

Also of interest within the current study were the correlations between alexithymia and the criterion variables. Alexithymia correlated significantly with both depression $(r=.38)$ and anxiety $(r=.46)$. The direction of these correlations suggests that people with a tendency toward emotional restrictedness also tend to have a higher degree of depressive and anxious symptoms. 
Although alexithymia and the factors of narcissism were considered to be predictor variables in the regression analyses, the relationships between these variables and other predictor variables also were important. High scores on spirituality along with concomitant high scores on alexithymia and/or narcissism could be indicative of spiritual bypass. Spirituality correlated significantly (and negatively) with alexithymia $(r=-.40)$, suggesting, as expected, that per- sons who reported higher levels of spirituality tended to be more emotionally expressive. Three of the factors of mindfulness also correlated significantly with alexithymia. Particularly noteworthy is a strong correlation between describing and alexithymia $(r=-.72)$. Additionally, Acting with Awareness $(r=-.36)$ and Nonjudging $(r=-.31)$ subscale scores correlated significantly with alexithymia. In contrast with this, narcissism seemed to have much weaker correlations with the criterion variables and the other predictors.

Before the regression analyses were computed, four assumptions of multiple regression were assessed. First, inspections of data plots, skew, and kurtosis suggested that the study variables were normally distributed. Second, the assumption of linear relationships between the independent variables and the dependent variables was grounded in existing theory and research. Third, examination of the coefficient alpha data for each of the study variables supported that the third assumption - that variables are measured without error - was not violated. Fourth, a visual examination of the plots of standardized residuals provided evidence that the assumption of homoscedasticity was not violated.

Two hierarchical regressions were used, one with each criterion variable, to determine the amount of variance in each criterion variable that could be predicted. Furthermore, the order of the blocks was determined based on existing theory about spiritual bypass. After the first block, spirituality, was entered, each of the five factors of mindfulness was entered as a separate block, followed by blocks with alexithymia and narcissism, respectively. In this way, the unique contribution of mindfulness, alexithymia, and narcissism beyond the contribution of spirituality to the variance in depression and anxiety could be considered.

Results of the hierarchical regression analysis with depression as the criterion variable in Table 3. The eight predictor variables accounted for $29 \%$ of the variable in depression $(F=18.33, p<$ $.001)$. Spirituality, in and of itself as the first block, accounted for a statistically significant but modest portion of the variance $\left(\mathrm{R}^{2}\right.$ adj $\left.=.07\right)$. These aspects of mindfulness (acting with awareness, nonjudging, and nonreacting) added to the prediction model with spirituality already in the model, with nonjudge having the strongest standardized coefficient of the mindfulness variables. Taken together, the mindfulness variables accounted for $20 \%$ of the variance in depression beyond the variance already accounted for by spirituality. Alexithymia, as the next block, added significantly to the prediction model. The final block entered, narcissism, failed to contribute significantly to the prediction model. By using criteria previously established for counseling research (Sink \& Stroh, 2006), the overall model had a large effect size.

Results of the hierarchical regression analysis with anxiety as the criterion variable are also presented in Table 3 . The eight predictor variables accounted for $37 \%$ of the variance in anxiety $(F=25.70, p<.001)$. Spirituality, in and of itself, accounted for statistically significant portion of the variance $\left(\mathrm{R}^{2}\right.$ adj $\left.=.11\right)$. Each of the five aspects of mindfulness added to the prediction 
model with spirituality already in the model, with nonjudge having the strongest standardized coefficient of the mindfulness variables. Taken together, the mindfulness variables accounted for $19 \%$ of the variance in anxiety beyond the variance already accounted for by spirituality. The final block entered, narcissism, also contributed to the prediction model, albeit with a small effect size. Again, the overall model had a large effect size.

\section{Discussion}

Depression and anxiety are two of the most pervasive mental health issues in U.S. society. Approximately 40 million Americans (about 18\% of the population 18 years or older are affected with some form of anxiety disorder, and approximately $6.7 \%$ of American adults experience a major depression in any given year (Kessler, Chiu, Demsler, \& Walters, 2005). Previous researchers, using paper-and-pencil measures of spirituality to assess how it is related to depression and anxiety, have found inverse relationships (Briggs \& Shoffner, 2006; Young et al., 2000). These researchers, however, have examined spirituality as the primary variable, focusing on the possible role of spirituality in predicting the symptoms of depression and anxiety. They did not consider the possibility that an individual may use spirituality or spiritual practices as a way to avoid working through painful life experiences. Because spiritual bypass is a phenomenon that takes place largely outside an individual's conscious awareness, paper-and-pencil measures of spirituality are unlikely to fully capture the function of spiritual practices in the lives of persons experiencing spiritual bypass. The current study extends previous research by considering not only spirituality but also constructs that may be indicative of spiritual bypass, specifically mindfulness, emotional restrictiveness (alexithymia), and narcissism.

Table 3

Hierarchical Regression analysis With Depression and anxiety as Criterion Variables

\begin{tabular}{|c|c|c|c|c|c|c|c|c|}
\hline \multirow[b]{2}{*}{$\begin{array}{l}\text { Predictor } \\
\text { Variable }\end{array}$} & \multicolumn{4}{|c|}{ Depression } & \multicolumn{4}{|c|}{ anxiety } \\
\hline & $\mathrm{b}$ & $\begin{array}{l}\text { adj. } \\
R^{2}\end{array}$ & $\begin{array}{l}\text { adj. } \\
\mathrm{D} R^{2}\end{array}$ & $p$ & b & $\begin{array}{l}\text { adj. } \\
R^{2}\end{array}$ & $\begin{array}{l}\text { adj. } \\
\mathrm{D} R^{2}\end{array}$ & $p$ \\
\hline Spirituality & -11 & .07 & .07 & .05 & -.17 & 11 & 11 & .00 \\
\hline Observing & .08 & .07 & .00 & .13 & .16 & .13 & .02 & .00 \\
\hline Describing & 08 & .10 & .03 & .27 & .18 & .16 & .03 & .01 \\
\hline Acting with & & & & & & & & \\
\hline Awareness & -.17 & .18 & .08 & .00 & -.12 & .23 & .07 & 01 \\
\hline Nonjudging & -.25 & .25 & .07 & .00 & -.24 & .30 & .07 & .00 \\
\hline Nonreacting & -15 & .27 & .02 & .00 & -.12 & .30 & .00 & .02 \\
\hline Alexithymia & .25 & .29 & .02 & .00 & .41 & .36 & .06 & .00 \\
\hline Narcissism & .01 & .29 & .00 & .84 & -.10 & .37 & .01 & .04 \\
\hline
\end{tabular}

Note. Adj. $R^{2}=$ adjusted $R^{2} ;$ Adj. $\mathrm{D} R^{2}=$ adjusted $R^{2}$ change.

The data provided evidence of adequate internal consistency on all measures for the current sample. Prediction models calculated using separate regression analyses for each of the two criterion variables (depression and anxiety) accounted for $29 \%$ and $37 \%$ of the variance in the criterion variables, respectively. Given the focus in previous research on examining the relationship between spirituality, depression, and anxiety, it is particularly noteworthy that spirituality accounted for only a 
small portion of the variance in the criterion variables. It is possible that the true relationships between one's spiritual life and symptoms of depression and anxiety are truncated by those respondents who are in spiritual bypass as measured in this study (i.e., score high on spirituality measure by having some combination of high scores on alexithymia, low scores on mindfulness, and high scores on narcissism). Of equal clinical significance is that three of the five facets of mindfulness were significant predictors of depression with spirituality already in the model, and all five facets of mindfulness were significant predictors of anxiety, again with spirituality already in the model. The constructs of acting with aware- ness, nonjudging, and nonreactivity seem particularly salient in understanding the phenomenon of spiritual bypass as it relates to depression and all five facets of mindfulness and also appear to be salient in assessing the spiritual lives of people who struggle with anxiety.

Alexithymia was a significant predictor toward both depression and anxiety. This is particularly noteworthy in light of the fact that alexithymia was entered as the seventh block in each model and still made a significant contribution to the variance of the criterion variable in both models. Because of the salience of alexithymia, it seems useful to consider strong correlates of alexithymia. For example, the data indicate particularly strong negative correlations (-.72) between describing and alexithymia. Spirituality (-.40) also was a strong correlate of alexithymia. Somehow the process of living a spiritual life and having the capacity to put your present-moment experience into words are related to a decrease in emotional restrictiveness. More research is warranted to further assess the process through which this occurs.

\section{Implications for Counseling Research and Practice}

As noted in the Competencies for Integrating Spirituality Into Counseling (Association for Spiritual, Ethical and Religious Values in Counseling, 2009), counselors should be able to assess the role that the religious and/or spiritual domains play in the client's therapeutic issues. Results of this study highlight the importance of specifically assessing for mindfulness, repression of emotions, and, in the case of clients presenting with anxiety and/or narcissism, to rule out spiritual bypass before formulating treatment plans when clients present that spirituality plays a critical role in their life. If counselors had included only spirituality, depression, and anxiety in the model, factors of spirituality would have been statistically significant predictors of both depression and anxiety, congruent with previous research findings (Briggs \& Shoffner, 2006; Young et al., 2000). Counselors would have missed, however, the importance of examining spirituality from a more holistic framework and the need for assessment to include factors of mindfulness and alexithymia in relation to clients' presentation of spirituality in relation to their presenting issues. Similarly, when a client presents with a strong positive sense of spirituality, counselors may not adequately assess for the possibility that the client is in spiritual bypass. Without effective assessment, counselors may develop treatment plans that include the continuation or increase of clients' current spiritual practices, which in turn would be counterproductive for clients who are actually in spiritual bypass.

Alexithymia and factors of mindfulness appear to form a cluster of predictors characterized as openness and the capacity for present-moment awareness and the ability to experience current thoughts and feelings. Taken together, this cluster of predictors contributes significantly to the prediction of depression and anxiety above and beyond the variance already accounted for by 
one's spirituality. Although additional research is needed to more firmly draw these conclusions, one possibility is that this cluster of being spiritually oriented, mindful, and emotionally open constitutes the buffer against external stressors that might occasion depression or anxiety.

For clients presenting with anxiety, then, it appears to be particularly important to assess for alexithymia and the five factors of mindfulness and to develop treatment plans based on this assessment. For clients presenting with depression, the mindfulness factors of nonjudging, acting with aware- ness, and nonreacting, along with alexithymia, may provide key insight into the client's inner world. It is important to note, however, that the results of the current study are correlational only and that the empirical question of whether changes in these factors of mindfulness and alexithymia will occasion positive changes in symptoms of depression and anxiety is beyond the scope of this study. Additional intervention studies are needed before this argument can be made.

However, these results do seem consistent with previous findings indicating that programs promoting mindfulness may reduce depression and anxiety (Grossman, Niemann, Schmidt, \& Walach, 2004; Miller, Fletcher, \& Kabat- Zinn, 1995; Reibel, Greeson, Brainard, \& Rosenzweig, 2001; Tacon, Caldera, \& Ronaghan, 2004). It is important to note, however, that other researchers have found less compelling outcomes of such programs (Toneatto \& Nguyen, 2007). It is unclear from previous literature how well-informed and trained practitioners were in using mindfulness programs with clients or how the specific interventions were chosen for use with specific clients. Counselors may do well to work with clients on developing individualized mindfulness practices rather than using "packaged programs." To do so, we would caution that counselors need to comprehensively assess how mindfulness may or may not relate to clients' depression or anxiety. In addition, as with all interventions, counselors need to understand the theoretical constructs underlying the interventions and be trained to use them.

\section{Recommendations for Future Research}

The current study represents only one effort to examine aspects of spiritual bypass and psychological well-being. There remains, however, a substantial amount of variance in both of the criterion variables for which the current predictors did not account. Additional projects could examine other aspects, such as spiritual materialism (Trungpa, 2002), self-esteem, dependence, and locus of control that may indicate spiritual bypass (Cashwell et al., 2004). Additionally, the sample for the current study was primarily traditional-aged undergraduate and graduate students. It may be useful to replicate or extend the current study by considering other populations, particularly considering the developmental phenomenon that many people may not mature into their personal and genuine spiritual life until after their college years. Finally, it is important to consider that the current research is correlational. Researchers have considered the impact of mindfulness training (e.g., Reibel et al., 2001; Tacon et al., 2004; Toneatto \& Nguyen, 2007) but have not systematically considered how the combination of predictors from this study, particularly mindfulness in conjunction with alexithymia, may be influenced to positively affect mood states.

\section{Limitations}


As with all research, it is important to consider the results of this study within the context of methodological limitations. The sample for this study was a convenience sample of students on two college campuses within one geographic area. It is unknown to what extent these results would generalize to all students, and it is even less clear whether these results would generalize to a nonstudent population. A second limitation is based on the reliance on self-report for this study. Such reports are subject to reporter bias and limits to self-awareness and self-knowledge. Finally, limited validity data were found for the measure of anxiety used in this study. Although the evidence of internal consistency was strong for this measure, results should be interpreted with caution in light of limited validity data.

\section{References}

Andresen, E. M., Malmgren, J. A., Carter, W. B., \& Patrick, D. L. (1994). Screening for depression in well older adults: Evaluation of a short form of the CED-D. American Journal of Preventive Medicine, 10, 77-74.

Association for Spiritual, Ethical and Religious Values in Counseling. (2009). Competencies for integrating spirituality into counseling. Retrieved from http://www.aservic.org/competencies.html

Baer, R. A., Smith, G. T., Hopkins, J., Krietemeyer, J., \& Toney, L. (2006). Using self-report assessment methods to explore facets of mindfulness. Assessment, 13, $27-45$.

Bagby, R. M., Parker, J. D., \& Taylor, G. J. (1994). The twenty-item Toronto Alexithymia Scale-I: Item selection and cross-validation of the factor structure. Journal of Psychosomatic Research, 38, 23-32.

Bagby, R. M., Taylor, G. J., \& Parker, J. D. A. (1994). The twenty-item Toronto Alexithymia Scale-II: Convergent, discriminant, and concurrent validity. Journal of Psychosomatic Re- search, 38, 33-40.

Briggs, M. K., \& Shoffner, M. F. (2006). Spiritual wellness and depression: Testing a theoretical model with older adolescents and midlife adults. Counseling and Values, 51, 5-20.

Cashwell, C. S., Bentley, D. P., \& Yarborough, P. (2007). The only way out is through: The peril of spiritual bypass. Counseling and Values, 51, 139-148.

Cashwell, C. S., Myers, J. E., \& Shurts, W. M. (2004). Using the Developmental Counseling and Therapy Model to work with a client in spiritual bypass: Some preliminary considerations. Journal of Counseling \& Development, 82, 403-409.

Cashwell, C. S., \& Young, J. S. (2005). Integrating spirituality and religion into counseling: A guide to competent practice. Alexandria, VA: American Counseling Association. 
Del Rosario, P. M., \& White, R. M. (2005). The Narcissistic Personality Inventory: Test-retest stability and internal consistency. Personality and Individual Differences, 39, 1075-1081.

Emmons, R. A. (1984). Factor analysis and construct validity of the Narcissistic Personality Inventory. Journal of Personality Assessment, 48, 291-300.

Grossman, P., Niemann, L., Schmidt, S., \& Walach, H. (2004). Mindfulness-based stress reduction and health benefits: A meta-analysis. Journal of Psychosomatic Research, 57, $35-43$.

Harper, M. C., \& Gill, C. S. (2005). Assessing the client's spiritual domain. In C. S. Cashwell \& J. S. Young (Eds.), Integrating spirituality and religion into counseling: A guide to competent practice (pp. 31-62). Alexandria, VA: American Counseling Association.

Howden, J. W. (1992). Development and psychometric characteristics of the Spirituality Assessment Scale (Unpublished doctoral dissertation). Texas Women's University, Denton.

Kessler, R. C., Chiu, W. T., Demsler, O., \& Walters, E. E. (2005). Prevalence, severity, and comorbidity of 12-month DSM-IV disorders in the National Comorbidity Survey replication. Archives of General Psychiatry, 62, 617-627.

Lehrer, P. M., \& Woolfolk, R. L. (1982). Self-report assessment of anxiety: Somatic, cognitive, and behavior modalities. Behavioral Assessment, 4, 167-177.

Meganck, R., Vanheule, S., \& Desmet, M. (2008). Factorial validity and measurement invariance of the 20-item Toronto Alexithymia Scale in clinical and nonclinical samples. Assessment, 15, 36-47.

Miller, J., Fletcher, K., \& Kabat-Zinn, J. (1995). Three-year follow-up and clinical implications of a mindfulness meditation-based stress reduction intervention in the treatment of anxiety disorders. General Hospital Psychiatry, 17, 192-200.

Parker, J. D. A., Taylor, G. J., \& Bagby, R. M. (2003). The 20-item Toronto Alexithymia Scale III: Reliability and factorial validity in a community population. Journal of Psychosomatic Research, 55, 269-275.

Princeton Religion Research Center. (2000). Americans remain very religious, but not necessarily in conventional ways. Emerging Trends, 22, 2-3.

Radloff, L. S. (1977). The CES-D scale: A self-report depression scale for research in the general population. Applied Psychological Measurement, 1, 385-401. 
Raskin, R., \& Terry, H. (1988). A principal-components analysis of the Narcissitic Personality Inventory and further evidence of its construct validity. Journal of Personality and Social Psychology, 54, 890-902.

Reibel, D. K., Greeson, J. M., Brainard, G. C., \& Rosenzweig, S. (2001). Mindfulness-based stress reduction and health-related quality of life in a heterogeneous patient population. General Hospital Psychiatry, 23, 183-192.

Scholing, A., \& Emmelkamp, P. M. (1992). Self-report assessment of anxiety: A cross validation of the Lehrer Woolfolk Anxiety Symptom Questionnaire in the three populations. Behaviour Research \& Therapy, 30, 521-531.

Sink, C. A., \& Stroh, H. R. (2006). Practical significance: The use of effect size in school counseling research. Professional School Counseling, 9, 401-411.

Stanard, R. P., Sandhu, D. S., \& Painter, L. C. (2000). Assessment of spirituality in counseling. Journal of Counseling \& Development, 78, 204-211. Tacon, A. M., Caldera, Y. M., \& Ronaghan, C. (2004). Mindfulness-based stress reduction in women with breast cancer. Families, Systems, \& Health, 22, 193-203.

Taylor, G. J., Bagby, R. M., \& Parker, J. D. A. (2003). The 20-item Toronto Alexithymia Scale IV.

Reliability and factorial validity in different languages and cultures. Journal of Psychosomatic Research, 55, 277-283.

Taylor, G. J., Bagby, R. M., Ryan, D. P., Parker, J. D. A., Doody, K. F., \& Keefe, P. (1988). Criterion validity of Toronto Alexithymia Scale. Psychosomatic Medicine, 50, 500-509.

Toneatto, T., \& Nguyen, L. (2007). Does mindfulness meditation improve anxiety and mood symptoms? A review of the controlled research. The Canadian Journal of Psychiatry, 52, 260-266.

Trungpa, C. (2002). Cutting through spiritual materialism. Boston, MA: Shambala.

Weissman, M. M., Sholomskas, D., Pottenger, M., Prusoff, B. A., \& Locke, B. Z. (1977). Assessing depressive symptoms in five psychiatric populations: A validation study. American Journal of Epidemiology, 106, 203-214.

Welwood, J. (2000). Toward a psychology of awakening: Buddhism, psychotherapy, and the path of personal and spiritual transformation. Boston, MA: Shambala.

Whitfield, C. (2003). My recovery: A personal plan for healing. Deerfield Beach, FL: HCI. 
Young, J. S., Cashwell, C. S., \& Shcherbakova, J. (2000). The moderating relationship of spirituality on negative life events and psychological adjustment. Counseling and Values, $45,49-57$.

* Correspondence concerning this article should be addressed to Craig S. Cashwell, Department of Counseling and Educational Development, University of North Carolina at Greensboro, PO Box 26170, Greensboro, NC 27402-6170 (e-mail: cscashwe@uncg.edu). 